\title{
Entrapped ulnar nerve by flexor carpi ulnaris tendon: case illustration
}

\author{
Marie-Christine Brunet, MD, FRCSC, and Hélène T. Khuong, MD, FRCSC \\ Division of Neurosurgery, Department of Neurological Sciences, CHU de Québec-Université Laval, Québec, Canada
}

https://thejns.org/doi/abs/10.3171/2018.5.JNS172840

KEYWORDS ulnar nerve; ulnar neuropathy; neural loop; Guyon's canal; peripheral nerve

A 57-YEAR-OLD right-handed female delicatessen worker presented with a 2-year history of progressive dominant-hand weakness. Ulnarsided wrist pain occurred with work-related repetitive wrist movements. Examination revealed severe ulnar clawing of the hand, with minimal ulnar-innervated intrinsic hand muscles function, normal flexor carpi ulnaris (FCU) and fingers flexor function, and normal sensitivity. Electrodiagnostic studies showed more significant changes in right distal ulnar nerve motor conduction than in sensory conduction, and active denervation in abductor digiti minimi and interossei muscles. MRI featured a focal signal abnormality of the ulnar nerve proximal to Guyon's canal without defined lesion.

Surgery at the distal forearm level revealed a splitting of the ulnar nerve with a neural loop passing through the FCU tendon before rejoining the main trunk proximally to the pisiform bone (Fig. 1A and B). Passive wrist motion resulted in traction of the ulnar nerve by the FCU tendon. The involved part of the FCU tendon, representing approximately one-fifth of the total tendon, was sectioned to release the neural loop (Fig. 1C and D). At 1-year follow-up the patient showed a significantly improved hand deformity with no pain recurrence, and electromyography confirmed reinnervation in the first dorsal interosseous muscle.

Entrapment of an ulnar nerve loop through the FCU tendon, although seldom reported, usually presents with wrist pain and sensory disturbance ${ }^{1,3}$ aggravated by hand use, ${ }^{4,5}$ whereas isolated motor presentation usually results from more distal entrapment at Guyon's canal, after the nerve branching. The constant location of the motor fascicle within the ulnar nerve in the forearm ${ }^{2}$ may explain the unusual presentation described in this report.

\section{References}

1. Al-Qattan MM, Duerksen F: A variant of flexor carpi ulnaris causing ulnar nerve compression. J Anat 180:189-190, 1992

2. Chow JA, Van Beek AL, Meyer DL, Johnson MC: Surgical significance of the motor fascicular group of the ulnar nerve in the forearm. J Hand Surg Am 10:867-872, 1985

3. O'Hara JJ, Stone JH: Ulnar neuropathy at the wrist associated with aberrant flexor carpi ulnaris insertion. J Hand Surg Am 13:370-372, 1988

4. Papierski P: Ulnar neuropathy at the wrist associated with a recurrent branch through the flexor carpi ulnaris tendon. J Hand Surg Br 21:347-348, 1996

5. Zook EG, Kucan JO, Guy RJ: Palmar wrist pain caused by ulnar nerve entrapment in the flexor carpi ulnaris tendon. J Hand Surg Am 13:732-735, 1988

\section{Disclosures}

The authors report no conflict of interest.

\section{Author Contributions}

Conception and design: Khuong. Acquisition of data: both authors. Analysis and interpretation of data: both authors. Drafting the article: Brunet. Critically revising the article: Khuong. Reviewed submitted version of manuscript: both authors. Approved the final version of the manuscript on behalf of both authors: Khuong.

\section{Previous Presentations}

Portions of this work were presented in poster form at the 82nd AANS Annual Scientific Meeting, San Francisco, California, May 2014. 

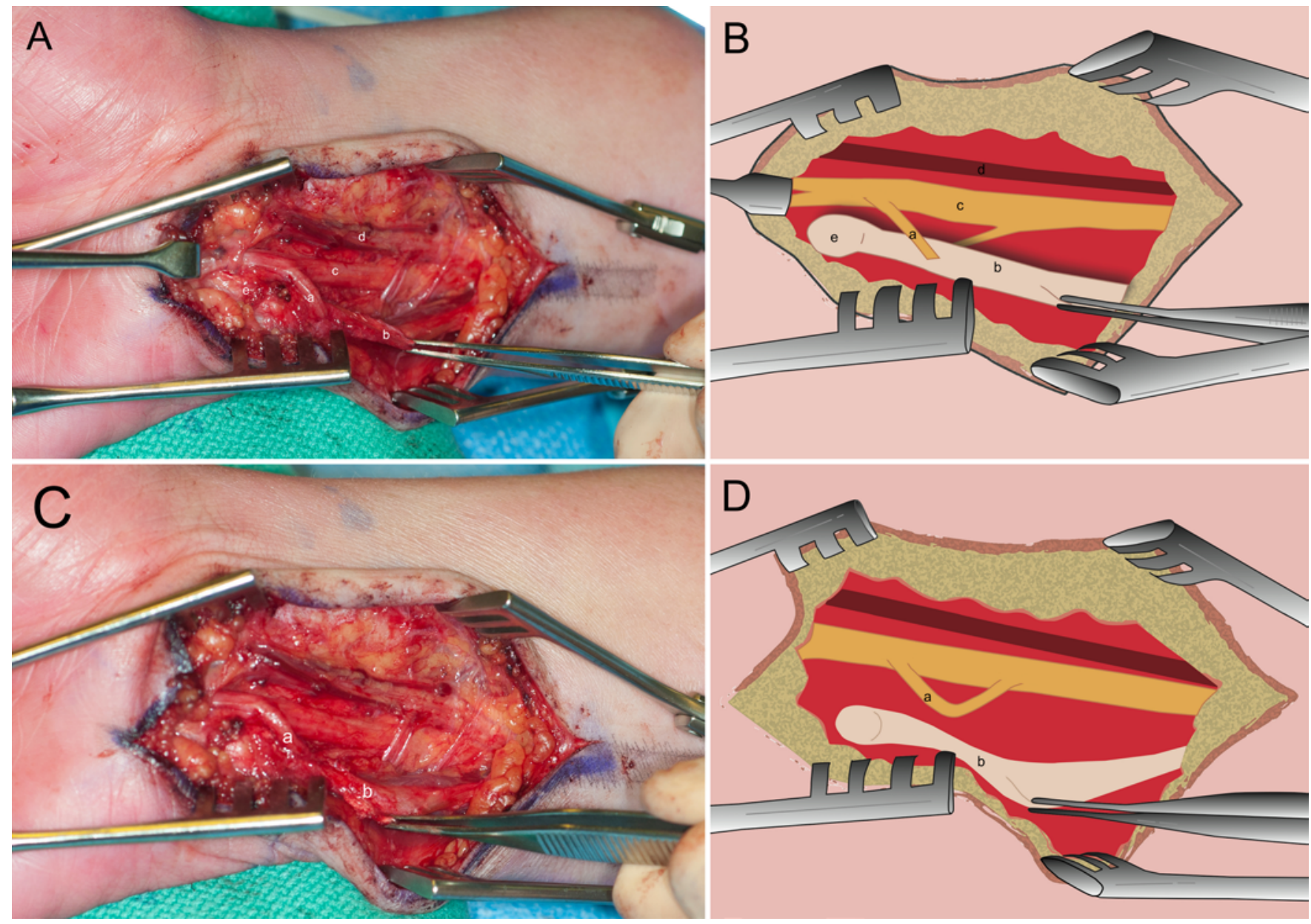

FIG. 1. Intraoperative photograph (A) and illustration (B) of an abnormal recurrent branch of the medial ulnar nerve (a) penetrating the FCU tendon (b) before joining the main trunk (c) and entering Guyon's canal along with the ulnar artery (d), at the distal forearm level. The FCU tendon was involved proximally to its insertion into the pisiform bone (e). Intraoperative photograph (C) and illustration (D) of the ulnar nerve loop (a) after its release from the FCU tendon (b). 